\title{
LA REINA MARÍA DE HUNGRÍA (1505-1558), UNA BIOGRAFÍA CON PERSPECTIVA DE GÉNERO ${ }^{1}$
}

\author{
Cruz María Martínez Marín²
}

La Reina María de Hungría (1505-1558), una biografía con perspectiva de género Resumen: El objetivo de este artículo es elaborar una biografía de María de Hungría analizando la figura de la Reina viuda como mujer en el poder. Para ello, se examinan algunos grandes trabajos sobre esta gobernadora de la Edad Moderna, conjugándolos con aquellas otras fuentes que recogen el peso de las expectativas a las que se enfrentaba como reina de Hungría, como hermana del Emperador, como viuda y como mujer.

Palabras clave: María de Hungría, Edad Moderna, mujeres en el poder, Habsburgo.

The Queen Mary of Hungary (1505-1558), a Biography with a Gender Perspective Abstract: This article aims to develop a biography of Mary of Hungary, focusing on the role of the widowed queen as a woman in power. In order to do so, seminal research of this Modern Age governor is examined and linked with other sources that reveal the expectations that she faced as queen of Hungary, as Emperor's sister, as a widow and as a woman.

Key words: Mary of Hungary, Modern Age, women in power, Habsburg.

\section{Introducción}

María de Hungría es la tercera hija de Juana de Castilla y Felipe de Austria. Al igual que sus tíos paternos y sus hermanos, sería una pieza política en manos de su abuelo Maximiliano, quien la prometió en matrimonio con tan solo seis meses de edad al heredero húngaro, el hijo de Vladislao, cuando este tan si quiera había nacido. La pequeña pues, creció con la seguridad de ser la futura reina de Hungría, esfuerzos a los que iba dirigida su educación, y que, por tanto, formaría una parte importante en la

\footnotetext{
${ }^{1}$ Fecha de recepción: 23/04/2018.

Fecha de aceptación: 05/12/2018.

${ }^{2}$ Personal Investigador en Formación, Departamento de Historia Moderna y Contemporánea, Universidad de Cantabria, Santander, España; $\square$ cruzmaria.martinez@unican.es. Este trabajo se enmarca en el Proyecto de investigación I+D del Ministerio de Ciencia, Innovación y Universidades HAR2016-77254P.
} 
concepción de su propia identidad, aunque tan solo lo fuera por escasos cinco años. Su corazón, sin embargo, quedó en los Países Bajos, donde vivió sus primeros nueve años de infancia. A pesar de los problemas a los que se enfrentó como mujer en el poder, contaba con algunos privilegios, era miembro de la dinastía que llegaría a convertirse en la más poderosa de Europa, y además recibió la mejor educación en humanidades, lenguas, literatura e historia posible. Sin embargo, su intervención directa en las decisiones políticas húngaras y, más tarde, su gobierno en solitario en los Países Bajos, la pusieron en una delicada situación en el contexto de la Europa del siglo XVI, que consideraba el gobierno y la monarquía asuntos eminentemente masculinos. María hubo de enfrentarse a una serie de convenciones y limitaciones, que en gran parte consiguió vencer con éxito. Gracias a su inteligencia logró en la práctica, gozar de una gran libertad de acción y decisión. El poder que logró dentro del Imperio no eliminó, sin embargo, el estrés y la indignación de encontrarse en esta lucha constante para afirmar su autoridad.

\section{Biografía}

\subsection{Infancia}

María era tan solo un bebé de cuatro meses cuando sus padres partieron a España a reclamar el trono, quedando al cuidado de su tía Margarita de Austria, quien se convirtió en una potente figura materna para la futura Reina de Hungría, dirigiéndose a ella en ocasiones como madre. En Malinas pudo disfrutar de la música borgoñona, así como de la antigua biblioteca de esta Corte y la de Saboya. Compartió tutores con sus 
hermanos, los españoles Juan de Achieta y Luis de Vaca y el organista de la capilla archiducal Hendrik Berdeniers (De Iongh 1958: 22-25). Se rodeó de los tesoros que coleccionaba Margarita, de los diseños de arquitectos y escultores que trabajaban en su monumento y de las conversaciones de eruditos y artistas que la frecuentaban. Sin embargo, la doble unión matrimonial que Maximiliano planeaba entre los hijos de Vladislao y sus nietos Habsburgo, se vio amenazada por la oposición de un sector húngaro, liderado por un noble, Juan de Zápolya. Debido a esta circunstancia, Maximiliano prepara una doble ceremonia de compromiso en Viena en la que él mismo representó el papel del prometido de la princesa Ana, entre otros motivos, porque aún no se había decidido si sería Carlos o Fernando. Con este acontecimiento se pretendía dar una apariencia de realidad al pacto y, tras el enlace, la princesa Ana y María residirían juntas en Viena. El conflicto vuelve en marzo de 1616 a causa de la muerte del Rey, se desata en Hungría una disputa entre los nacionalistas que querían nombrar a Zápolya regente hasta la mayoría de edad de Luis, y los leales a Vladislao II Jagellón, quienes demandaban que gobernara el consejo de regencia designado por él. Maximiliano envió tropas para proteger a Luis, y con él sus posibilidades de obtener el trono de Hungría para María, y trasladó a las niñas a Innsbruck.

Durante esos años, María disfrutaría de representaciones teatrales, y momentos de caza con el Emperador cuando éste acudía a visitarla. Su pasión por el deporte parecía heredada de sus abuelos paternos María de Borgoña y Maximiliano de Austria. Cuando Innsbruck recibió la visita del embajador veneciano Gasparo Contarini, éste quedó muy impresionado por la voluntad enérgica y juicio de María, reportando en su informe de gobierno que la Princesa parecía poseer una gran inteligencia y que sería una mujer importante (De Iongh 1958: 47). 
Luis había tenido que rechazar el pacto de sucesión con Austria públicamente para obtener su corona, y durante los años siguientes renegociaría con Carlos los matrimonios. El 11 de diciembre de 1520 se celebró otra doble ceremonia de compromiso en la que Wilhem von Roggendorf actuó en representación de Fernando, en tanto que Ambrus Sárkány sustituyó al rey Luis. El doble enlace fue bendecido en la pequeña Iglesia de San Jacobo. Ana y Fernando se casaron en Linz en mayo de 1521, donde María conoció a su hermano por primera vez. Ambos acababan de embarcarse en sus carreras políticas y a pesar de haberse criado en tan diferentes cortes, descubrieron que compartían gustos e intereses y entre ambos se formó un vínculo estrecho y duradero. Tras este contacto, María partió a Viena, donde fue escoltada a la frontera húngara para reunirse por fin con el que había de ser su marido. Sin embargo, mientras estaba de camino, a la altura de Buda recibió mensajeros informando de un peligro extremo en Hungría. Suleiman II, el Gran Turco, se aproximaba a la frontera con sus tropas y a causa de ello el rey no debía abandonar Buda, por lo que no estaba acudiendo a su encuentro. Además, los mensajeros transmitieron el deseo del rey de que María esperara en Bratislava y no continuara su viaje hacia Buda dadas las circunstancias. Indignada, rechazó la petición de Luis e hizo alarde de su título como reina de Hungría para ordenar que la llevaran a Buda. Los mensajeros se fueron y volvieron con nuevas sugerencias. Le ofrecieron ir a Estrigonia o a Visegrado, lugares donde el Rey podría visitarla, pero su determinación era clara: si Luis estaba en Buda, ella debía estar en Buda también. El embajador vienés apreció su tono y determinación y más tarde reportaría a su gobierno la fuerte personalidad de la joven reina. Su deseo se impuso y así su viaje terminó en la capital. 


\subsection{Tensiones en Buda}

En la corte de Hungría los nobles disfrutaban de tal lujo y esplendor que hacían parecer a Luis un mendigo. Él era un niño y los miembros de su corte habían acaparado el poder y robado dinero de las arcas. María supo ver la enemistad que le rodeaba y trabajó por los intereses de su esposo, financiando de su propio bolsillo la renovación de su vestuario en mal estado. Tuvo que pelear con oportunistas y damas de compañía que se habían instalado en palacio y se habían quedado con las mejores habitaciones, y que ahora tuvieron que enfrentarse al temperamento de María. Hanns Schweinpeckh, uno de sus miembros de corte austriacos, escribió que una mujer estaba enfurecida por tener que dejar su habitación. María la echó, aunque no fuera a dar uso a la estancia, porque la reina sabía que si no se mostraba como ama sería para siempre sirviente (De Iongh 1958: 69). Además de encargar nuevos ropajes para Luis, María usó su dote para transformar la corte real húngara en un centro modélico del humanismo borgoñés. En estas fechas no era extraño que las mujeres gozaran de una cierta libertad a la hora de usar su propia dote para sus intereses, sin embargo, el ascenso del sistema centralizado de gobierno restringió el régimen señorial, limitando la oportunidad de ejercer autoridad en cortes feudales a las damas (Doyle 1996: 205).

María se convirtió en reina en tiempo de crisis, enfrentándose a la invasión turca y a su oposición en la corte. El país iba a ser atacado, no era el momento apropiado para celebrar la boda. Escribió cartas a sus hermanos, el emperador Carlos y el Archiduque Fernando, exhortándolos a hacer las paces con todos los príncipes de la cristiandad, para que juntos pudieran defenderse del peligro turco de Hungría y Europa (Doyle 1996: 205). Sus oponentes extendieron el rumor de que la reina regresaría a Austria si los 
turcos atacaban, buscando su propia seguridad, para provocar el odio del pueblo húngaro contra su reina. Pero María no concebía escapar y dejar a Luis y su país en peligro. Viajó hacia Adony acompañada por Andrea da Burgo, puesto que sabía que las tropas estaban reunidas allí y apareció enérgica, montando en un fiero caballo que manejó sin dificultad, para inspeccionar las tropas. Disipando cualquier duda de que fuera a huir, se colocó junto a los oficiales listos para la batalla. Los húngaros la recibieron con aplausos e hicieron sonar las trompetas. Mientras luchaban avanzando hacia el este, les llegaron noticias de que el sultán Suleiman no emprendería ninguna campaña hasta el invierno, sus tropas estaban en retirada (De Iongh 1958: 72).

El país pide que declaren a su rey mayor de edad, y finalmente la boda se lleva a cabo el 13 de enero de 1522. El 8 febrero de 1522, María firma el documento que la hace heredera de Hungría y Bohemia. Su poderosa presencia en la corte desató críticas, la oposición a la unión de la corona con la dinastía austrohúngara extranjera seguía presente, y además estaba el hecho de que tradicionalmente en la corte de Buda la reina había estado ausente. En los 86 años transcurridos entre 1440 y 1526, tan solo 26 de ellos Hungría tuvo una reina que residiera en la corte, normalmente la Casa de la Reina no compartía espacio con ésta (Réthelyi 2008: 17). Su llegada supuso que la corte de Buda hubiera de transformarse de una corte puramente masculina a una mixta (Réthelyi 2008: 20).

Entre 1522 y 1524 la amenaza otomana dio un respiro, dejando a María y Luis tiempo para disfrutar su reinado, aunque éste quedó ensombrecido por las acusaciones de extravagancia, el recelo con el que fue vista su actividad religiosa por su cercanía a Martín Lutero y la ausencia de un embarazo. María demuestra en este reinado su interés por las artes, el testimonio de algunas descripciones y un sillar con su nombre inscrito, 
indican que comisionó reformas artísticas en el castillo. En general las empresas artísticas se intensificaron con su llegada a la corte, lo que le supuso críticas, pues había quien opinaba que las fuentes de dinero invertidas en esto deberían de ser empleadas en la defensa contra el Imperio Otomano. A través de las cartas privadas sabemos que programaba grandes fiestas, torneos y cacerías, formas todas en las que se demostraba el esplendor de la Corte. Hans Krell, autor de dos retratos de los reyes, recibió encargos entre 1522 y 1526 , que incluían la decoración de estos torneos, cacerías y banquetes (Réthelyi 2008: 22).

Los tratados acerca del comportamiento ideal de las mujeres consideraban que una dama cortesana debía ser inteligente, pero solo lo suficiente, pues se consideraba peligroso una educación elevada (Kelly 1984: 34). Como mujer en un cargo público en el siglo XVI, el estilo de vida de María entraba en conflicto con un considerable número de estándares sociales y legales (Doyle 1996: 201), y conforme avanzaban las décadas, aumentó el número de leyes y códigos administrativos por toda Europa que excluían a las mujeres de la política. Hubo de soportar especulaciones y críticas ante la falta de herederos del matrimonio. Vicenzo Giodoto la consideró estéril a causa de su activo estilo de vida y su débil constitución. Se rumoreaba sobre la existencia de un hijo ilegítimo de Luis II y eso hizo cargar toda la culpa a María de la ausencia de embarazo (Réthelyi 2008: 19). La descendencia es una cuestión dinástica crítica. No aportar nuevos miembros a la dinastía afectaba a su popularidad en el reino. Sin un heredero, continuaba siendo vista como una representante de los intereses Habsburgo, mientras que con un bebé su lealtad estaría con Hungría. Por ello, las acciones de María debían demostrar la defensa de los intereses del reino, por encima del rechazo que producía su origen extranjero y su aparente incapacidad de concebir. 
A pesar de que la ley húngara restringía el acceso a puestos en la corte a extranjeros, en los primeros años del reinado de María de Hungría, la Corte de Buda estuvo constituida únicamente por nobleza de los Países Bajos y Austria que la acompañó a Hungría. Con astucia, y teniendo en cuenta las tensiones y ambiciones de la nobleza húngara para no mostrarse como una reina extranjera y limitar el poder de los nobles opositores, comenzó a concertar matrimonios entre las damas nobles a su servicio con miembros de la nueva aristocracia húngara, reforzando así el poder real. Además, colocó en puestos claves de la administración de los estados a miembros de la baja nobleza, estando ausente, en principio, la antigua aristocracia en la Corte (Réthelyi 2008: 22-23). María convenció a Luis para convocar una reunión en la Dieta de Bohemia, donde los nobles podían presentar protestas a su coronación. En ella consiguió no solo su aprobación, sino además reforzar el ejército real. Esto último fue primordial para el reino puesto que los turcos acababan de conquistar Rodas, con lo que era bastante probable que volvieran su atención hacia Hungría de nuevo. Pensando en este peligro y a pesar de su estrategia de exclusión de la vieja nobleza, la reina decidió, para sorpresa de todos, poner en la corte a partidarios de Juan Zápolya para que éste le apoyara militarmente contra los turcos y engrosar así su ejército en caso de guerra (De Iongh 1958: 72).

Tras esta segunda fase en la que coloca al enemigo en la corte, incorpora igualmente nuevos cortesanos extranjeros afines a ella. En su correspondencia con Alberto de Brandeburgo le pide constantemente que le suministre gente de confianza y sabemos por una queja al archiduque Fernando en 1523 que la reina llegaría a tener repartidos por la corte y en el servicio a alemanes, italianos y españoles (Réthelyi 2008: 22). Sus esfuerzos se concentraron en la centralización y refuerzo del poder real, 
defendiendo al reino incluso de los intereses de su hermano, el archiduque Fernando (Réthelyi 2008: 20). Esto no era para nada habitual, los tratados de los siglos XIV y XX definían a la esposa ideal como un complemento de su marido cuyo cometido era proveer a éste de herederos, no ejercer verdadero poder económico o político. María demuestra ser una aliada política de Luis, no únicamente su mujer. De hecho, llegó a convertirse en la figura dominante de la corte húngara, su recomendación fue considerada un gran respaldo incluso para audiencias en España y Alemania (Doyle 1996: 209). A pesar de que la historiografía siempre ha resaltado el papel de María como obediente hermana al servicio del Imperio, en secreto tanteó a diversos cortesanos para que apoyaran a Luis II en lugar de a Fernando a la hora de adquirir el título de Rey de los Romanos (Csepregi 2005: 4). De esta manera antepone su marido a su dinastía, hecho que habla de la ambición propia de María como reina de Hungría. En cualquier caso, este suceso demuestra que no todas sus acciones tenían una intención tan evidente y a veces se anteponía a sí misma frente a la dinastía, o bien a Hungría o a los Países Bajos frente al resto del Imperio austrohúngaro, como veremos más adelante.

Pese la victoria táctica de María de tener de su lado a los nobles antagonistas a la corona, los pactos durarían poco, ya que cuando los turcos hicieron avanzar su ejército en 1526, los viejos problemas resurgieron y la puesta en marcha del ejército se retrasó. Zápolya no unió sus fuerzas con el rey, apelando a la necesidad de defender Transilvania, y Luis hubo de enfrentarse solo. A pesar de que el rey tenía una ventaja numérica, su ejército fue destruido, Luis fue asesinado y los turcos invadieron la mayor parte del país, de tal modo que, con veintiún años y pese a sus esfuerzos, María se convierte en una reina viuda de un reino conquistado (De Iongh 1958: 74). Frente a la actitud negativa y de oposición hacia reina en sus primeros años, sus acciones ganaron 
el respeto de los húngaros, haciendo que Johannes Henckel, sacerdote de la corte, confesara en una carta a Andreas, gobernador de Kassa, que "desearía que la transformación fuera posible, y la Reina se convirtiera en el Rey" ya que "el destino del reino habría resultado mejor parado" (Heib 2009: 20). De sus últimos años de reinado anteriores a la guerra Sebastian Justiniani, el cual había sido uno de sus mayores críticos frente a la ausencia de herederos, afirmó "la autoridad del rey es muy escasa, pero la reina gustó a los húngaros, y durante dos años sería el rey y la reina en una sola persona" (Réthelyi 2008: 15). Tal era la aprobación que la reina había logrado, que casi unánimemente la nobleza deseó que continuara gobernando en calidad de Regente. Su hermano Fernando también supo apreciar la brillantez de su gestión de gobierno y apoyó el que ocupase este puesto, aunque María tenía otros intereses (Réthelyi 2008: 20).

\subsection{La Gobernadora viuda}

Si la política Habsburgo podía quedar resumida en su lema "Bella gerant alli; tu, felix Austria, nube" (Hagan otros la guerra; tú feliz Austria, cásate), ya que su Imperio se levantó de la nada gracias a una acertada política matrimonial en tres generaciones, María consigue librarse de volver a ser utilizada como peón de dichas estrategias. Cuando queda viuda jura a sus hermanos, sometiéndose al pater familias, Carlos, a su autoridad, y en menor medida a la de su hermano Fernando. Vuelve a la jerarquía familiar Habsburgo y, sin embargo, rechaza no una sino dos peticiones por parte de sus hermanos, la de Carlos de unirse en matrimonio con Jaime V de Escocia y la de Fernando de quedarse como Regente en Hungría. Comenzamos a ver la personalidad de 
la "obediente" hermana que se arrodilla frente al Emperador, pero que en la práctica actúa conforme a su propia voluntad. Con una astucia natural para las relaciones diplomáticas y la política, María muestra la determinación e inteligencia necesarias para hacer valer sus intereses. Anuncia, tras declinar ambas ofertas, que su fin habría de ser servir al emperador directamente, al igual que su tía Margarita (Réthelyi 2010: 130).

María había sido formada en el ideario religioso y cultural de la devotio moderna, y cuando enviudó optó por una forma de vida religiosa, al estilo de las viudas beatas, que acentuaría con la llegada de su hermana Leonor (Réthelyi 2010: 162-162). De este modo, su imagen pública cambiaría para siempre, a partir de ahora todos sus retratos la mostrarían con su habitual atuendo de viuda severo y austero. Su imagen será continuación de la mostrada por Margarita de Austria y servirá como modelo a Isabel Clara Eugenia. Los paralelos entre su vida y la vida de Margarita en su deseo de mantenerse viuda y servir a sus hermanos es un signo evidente de que deseaba emular el rol de su admirada tía. Que mostrara su deseo de servir al emperador y especialmente en el Este, daba cuenta de que María ya había contemplado suceder a Margarita como Regente de los Países Bajos (Doyle 2006: 18). Aunque la viudez era probablemente el estado que más libertad podía conferir a una mujer de alta cuna en esta época, era muy complicado verse totalmente libre de ataduras, normalmente la familia de sangre esperaba que la dama se volviera a casar para forjar una segunda alianza, en tanto que la familia política quería mantener el control de la riqueza de la viuda, especialmente cuando había nietos de por medio (Klapisch-Zeuber 1987: 120). Por suerte, María solo conservaba a su cuñada, Ana de Hungría y Bohemia, como familia política, y además no tuvo hijos en el matrimonio. Las viudas eran las mujeres con más autonomía económica al no estar sujetas a padre o marido, suponían un caso especial, y María lo conocía de 
primera mano a través de su tía Margarita, por lo que trató de seguir su ejemplo.

El hecho de que Carlos se casara por segunda vez podría interpretarse como un síntoma de que tenía planeado ocuparse de la Regencia en los Países Bajos él mismo, y también hay algún que otro rastro de estos planes en su correspondencia: en dos meses y medio se carteó cinco veces con su tía. Sin embargo, María prepara el terreno. En la dieta de Augsburgo en Innbruck de 1530, María discute con Fernando la posibilidad de suceder a Margarita de Austria, sin sospechar que seis meses más tarde sería un tema de urgencia debido a su fallecimiento (Gorter-van Royen 2008: 30). La pérdida de su querida tía y madre se une a la de su abuelo y su marido. A pesar de todo, María mostraría siempre una enorme fortaleza ante la adversidad y la soledad. Con la muerte de Margarita, Fernando propone a María como sucesora ante Carlos. El Emperador se la ofrece formalmente el cargo a su hermana el 3 de enero de 1531 y el 28 de este mes, ella acepta. Su nombramiento como tal hace que los problemas de la sucesión al trono de Hungría se reduzcan, María actuó en beneficio de la coronación de Fernando y Ana con éxito, abandonando la regencia en Hungría para asumir la de los Países Bajos (Doyle 2006: 18).

Debido a la ley húngara conservó derechos y propiedades en Hungría, con lo que mantuvo influencia política en Hungría y derechos soberanos. La figura del rey, que en este caso era su propio hermano, tenía obligación con las reinas viudas mientras vivieran. En la Dieta de Bohemia, María le comenta a Fernando que podía retirar su pensión, pero su hermano reconoce carecer de poder para alterar sus derechos como viuda en Hungría y solo a su muerte pudo repartir las propiedades y derechos soberanos que María conservaba en Hungría (Doyle 2006: 213). Como Regente en los Países Bajos, María tuvo que hacer estable su gobierno permaneciendo firme en su rol 
dinástico familiar y respetando a su vez las tradiciones locales. Ejercería un papel muy importante en la propaganda artística del Emperador, llegando a configurar parte de la iconografía que caracterizaría por siempre a la monarquía española (Van den Boogert 1993: 249). En Hungría María había contemplado la ambición de los nobles y aprendido el arte de la negociación, durante sus años como reina de los Países Bajos demostraría ser una astuta gobernadora, sembrando espías en las diferentes cortes europeas para adelantarse a sus enemigos. Siguió el ejemplo de Margarita al crear una Casa de la Reina independiente (Doyle 2006: 214). En su deseo de mostrar su identidad y desmarcarse de la anterior regente, decide establecer su corte en el antiguo palacio de los duques de Bramante en Turnhout, que reformó, en lugar de en el palacio de Margarita de Austria en Malinas. Su intención era trasladarse más adelante al palacio de Binche, creación propia de nueva obra que se convertiría en referencia para otras cortes europeas.

Trabajará junto con su hermana Leonor, casada en ese momento con Francisco I de Francia, aprovechando el parentesco, para tratar la paz entre Carlos y el rey francés logrando, a partir de 1532, establecer un canal de comunicación entre las cortes de Francia y los Países Bajos que sería fundamental para pactar futuras treguas. De su pericia política dan cuenta las relaciones diplomáticas y comerciales que logró establecer para los Países Bajos con Inglaterra, a pesar de la ruptura definitiva de Carlos y Enrique VIII (Doyle 2006: 25). No dejó que su orgullo obstaculizase su habilidad para ganar poderosas amistades y establecer una larga red clientelar a través de Europa (Doyle 2006: 205). Descrita en una ocasión como "la más belicosa mujer que había conocido nunca" por un embajador inglés, María solía inspeccionar las tropas por ella misma, ganándose el respeto de los mejores capitanes de Carlos por su experiencia y 
pericia en asuntos militares. A menudo sus sugerencias fueron frustradas ante la negativa de Carlos o por la imposibilidad de mandar tropas o dinero (Thompson 1975: 32). Cuando la guerra fue inevitable, la reina prestó su apoyo militar estableciendo un pacto de ayuda mutua entre Alemania y los Países Bajos. De su papel como estratega militar resaltamos el rol de comandante que hubo de ejercer a finales de 1541: los ejércitos de sus hermanos estaban ocupados librando batallas contra los turcos, momento que sus rivales políticos en Europa aprovecharon para atacar a los Países Bajos por todos los flancos. Francia invadió el oeste y el sur, Cléveris atacó en el norte y los daneses Holanda y Zelanda. María se enfrentó a ellos sin apoyo exterior. Fue capaz de reunir la defensa de los Países Bajos, logró frenar el ataque y más que eso, contraatacó, haciendo que los ejércitos enemigos se batieran en retirada (Doyle 2006: 32-33). A pesar de su capacidad, se excusa por volver a participar en estrategias bélicas, explicando en una carta al Emperador que "la experiencia me ha enseñado que la guerra no es asunto de mujeres" y "como mujer, me veo obligada a dejar el desarrollo de la guerra a otros". Tras estas afirmaciones se esconde la frustración por las muchas limitaciones con las que tenía que lidiar, puesto que no estaba permitido que una mujer comandara los ejércitos y tomara parte en esta materia, por lo que nunca se le reconoció debidamente su participación (Monter 2012: 102).

Otro aspecto que se ha discutido es el papel que María de Hungría desarrolló ante la Reforma luterana. Al parecer se mostró profundamente interesada en las controversias espirituales que había despertado la Reforma, interviniendo en las polémicas teológicas, tuvo como principales consejeros a Jean Carondelet, arzobispo de Palermo; al humanista y diplomático Cornelio Schepper y al obispo húngaro Miklós Oláh, todos ellos de tendencia erasmista (Gonzalo Sánchez-Molero 2008: 161). Carlos de 
Münsterberg y Johannes Henckel también fueron invitados con motivo de la reforma.

Se ha hablado también de su relación con Stolzer, su maestro de capilla, pero es más lógico suponer que su interés se debiera más a sus capacidades musicales que a sus ideas luteranas (Réthelyi 2010: 182). En general, aunque nunca actuó en contra de la línea católica del Imperio, su simpatía con los protestantes horrorizó a sus hermanos debido a los rumores. Su interés por los conflictos religiosos de la época es extraordinario ya que este terreno solía estar vetado a las mujeres, a las que se les negaba educación teológica (Doyle 2006: 217), pero tal como afirmó en una carta de su propia mano a Alberto de Brandeburgo en septiembre de 1522, María deseaba "enterarse de todo"3 (Csepregi 2005: 1). La reina acogió con agrado a los debates del periodo en su corte y se interesó por igual por las artes y las ciencias (Doyle 2006: 20). Su inquietud intelectual se demuestra en todas las publicaciones recientes que recibía (Splingart 1994: 40). Sus coetáneos dejaron testimonio de que la reina siempre tenía un libro en sus manos, y sus cartas reflejan su forma irónica de escribir (Réthelyi 2010: 84, 87).

La regente también tuvo problemas en su gobierno en los Países Bajos, con los que consiguió lidiar imponiendo sabiamente su autoridad frente a las revueltas internas. Supo representar brillantemente los intereses políticos de los Países Bajos en el panorama europeo ofreciendo de cara al exterior una imagen de unidad territorial, estableció relaciones con potencias extranjeras y los protegió de las excesivas peticiones de su hermano, además trabajó para velar por el interés de ellos en su conjunto apelando a la lealtad dinástica (Réthelyi 2010: 42, 46). María sufre una gran tensión respecto esta

\footnotetext{
${ }^{3}$ La cita original es "Ich will alle ding wol erfaren". Erfahren tiene varias connotaciones tales como enterarse, aprender, experimentar o conocer. Podría decirse que una de las grandes ambiciones de la reina era el conocimiento, el cual pretendía alcanzar a través de la lectura, pero también de los debates que invitaban a analizar un asunto desde diversos puntos de vista y buscar puntos de encuentro en el discurso para lograr soluciones.
} 
doble lealtad para con los territorios en los que gobernaba y su familia. En una carta a Carlos poco antes de anunciar el fin de su regencia expresa: "cuanta más experiencia tengo, más me doy cuenta de que soy incapaz de cumplir mi deber apropiadamente. Actuar como Regente de un soberano requiere más conocimiento de los asuntos que gobernar en solitario" puesto que "una Regente debe cuentas no solo a Dios sino también a su soberano y a los asuntos del soberano. (...) En ocasiones he hecho más de lo que correspondía a mi posición y de lo que se esperaba de mí como mujer" (Monter 2012: 101).

Cuando en 1548 su hermana Leonor quedó viuda, María la acogió, y en 1549 ambas acompañaron a Carlos y Felipe en el viaje real de la presentación del Príncipe, para cuya recepción reformó su palacio en Binche cuidando su programa iconográfico. La reina estaba en la cúspide del poder como clave del Buen Gobierno y disfrutaba de la plena confianza de Carlos. Un año más tarde, en la cumbre de la familia Habsburgo, para la que encargó a Tiziano un retrato familiar, María actuaría como mediadora entre sus hermanos, dividiendo el título imperial entre las dos ramas de su familia (Doyle 2006: 37). La basta influencia que María era capaz de ejercer sobre Carlos resultaba a veces escandalosa y provocó un gran número de quejas. Acusada de ser demasiado agresiva y de no tratar con suficiente respeto a "sus superiores", el Cardenal Granvela reflejaba con amargura en su correspondencia que María de Hungría sobrepasaba sus funciones y violaba los privilegios y derechos de otros, y es que la regente pensaba que debía responder ante sus hermanos (Doyle 2006: 221-222).

La Regente no solo apoyó a Carlos militarmente, más importante aún fueron sus consejos. Casi nunca erró en el juicio, pero no siempre el Emperador hizo caso de sus recomendaciones. A menudo se quejaba de esto a Fernando en sus cartas, poniendo en 
duda la inteligencia de su hermano (Doyle 2006: 40). Las tropas de Carlos se volvieron contra él en 1552, cuando éste planeaba usarlas contra los turcos, momento que ejemplifica cuan clave sería el consejo de María. Los príncipes alemanes tenían muchas discrepancias con el Emperador, en especial en lo tocante al protestantismo. Un ejército alemán comandado por Mauricio de Sajonia le hizo frente y Carlos quedó indefenso en Alemania. Pensó en huir a los Países Bajos para liderar su ejército, pero su hermana le advirtió que si no resistía en Alemania perdería su Imperio, lo que con toda probabilidad habría resultado ser cierto. En ésta y otras ocasiones María se muestra como un "oráculo", tal y como la describe su elogio fúnebre (Monter 2012: 103), por su capacidad de anticipar sucesos y actuar en consecuencia. A pesar de que Carlos no huyó, finalmente no supo manejar a sus hombres, y necesitó la intervención de Fernando como mediador. Con un nuevo ejército español e italiano reunido por Fernando se enfrentó a los turcos con un fracaso estrepitoso que acabó con su reinado en cierta manera, puesto que quedó enfermo y deprimido. Tras esto María tomó las riendas del gobierno de Carlos en muchos sentidos, tomó el control de la administración imperial y trabajó junto a Felipe en una alianza contra los franceses, obteniendo también el apoyo inglés.

En 1555 renuncia a la regencia en una pesimista carta donde se lamenta de que "una mujer nunca es tan respetada y temida como un hombre, sin importar qué rango ostente" (Monter 2012: 94). Pese a esto, cuarenta y cinco años más tarde, los Estados Generales de los Países Bajos aún recordaban con nostalgia los “dorados viejos tiempos" de la regencia de María de Hungría (Monter 2012: 111). A pesar de que no fue marginada del poder, no por ello dejó de sufrir los efectos de los privilegios y consideraciones sociales. Su autoridad y estilo de vida fueron cuestionados a causa de 
su sexo desde muy temprana edad. María se preguntaba en algunas cartas a su hermano el Emperador si su vida no sería demasiado pública y se muestra preocupada por las contradicciones entre las expectativas sociales y su forma de actuar (Doyle 2006: 220). Efectivamente, su participación en el espacio público, económico, político, social y religioso entraban en conflicto con los estándares sociales del periodo, que relegaba a las mujeres al espacio privado (Doyle 2006: 216-217). En todas sus caracterizaciones, se la describe como una actriz política (Doyle 2006: 203), tal y como se dice de su sobrino Felipe II, dado que en ocasiones debía modular su comportamiento y mostrarse de una determinada manera para legitimar su poder, como demuestra el que portara hasta su muerte la túnica de viuda que señalaba su pertenencia a la dinastía familiar. Una apariencia lujosa y llamativa habría ido en contra de la modestia y decoro que cabía esperar en una dama viuda. Y sin embargo sí que dio rienda suelta a su afición por el lujo cortesano, siguiendo y ampliando el modelo asentado por su tía Margarita de Austria, aunque, de nuevo, no sin crítica (Sebastián Lozano 2005: 178).

\section{4. Últimos años}

En septiembre de 1555 Felipe acudió a los Países Bajos para hacerse cargo de su gobierno y en enero de 1556 Carlos abdicó con lo que las dos hermanas y el antiguo emperador se embarcaron hacia su retiro en España. En este país, Leonor y María buscaron poder alojarse en un palacio donde desarrollar una vida cortesana como dos notables viudas al estilo de Flandes. Escogieron residir en el palacio del Duque del Infantado en Guadalajara e intentaron que la joven infanta María de Portugal se les uniera. Ésta se negó a abandonar Portugal y esto, sumado a la muerte de Leonor en 1558, truncó el proyecto de la que habría sido una corte femenina sin precedentes en 
España (Gonzalo Sánchez-Molero 2002: 475-476). Aunque ya retirada, Carlos continuó valorando los consejos de su hermana, incluyendo su opinión acerca del gobierno español. Este hábito dejaba atónita a Juana de Austria, que se quejaba constantemente a su hermano, Felipe II. En una de sus cartas comenta que: "el carácter de la Reina de Hungría es tal que no se contenta con ofrecer consejo, sino que desea tomar el mando, y mi autoridad de gobierno no puede soportar estos cambios... Preferiría retirarme y renunciar a la regencia de España" (Monter 2012: 102).

En sus últimos meses de vida, María de Hungría continuó comprando esculturas y libros y preparando nuevos proyectos, pero la muerte le sorprendió el 10 de octubre de 1558, tan solo veinte días después de la muerte de Carlos (Estella Marcos 2000: 321322). Su funeral se celebró en la Catedral de Santa Gúdula, rodeada de las vidrieras que exhibían la representación de miembros de la dinastía Habsburgo que ella había encargado a Bernard van Orley. François Richardot la colmó de elogios, "tanto en asuntos públicos como de gobierno, María dio prueba clara de una mente extraordinaria, facilidad de comprensión, destreza y consejo, mostrando energía y vivacidad en todo: en sus discursos, sus opiniones y sus juicios. Como regente novicia, mostró devota e increíble energía y diligencia para entender los asuntos públicos de los Países Bajos: en poco tiempo aprendió y entendió todos los aspectos incluso mejor que aquellos que hasta entonces habían manejado dichos asuntos. Este fue uno de sus más admirables rasgos: la cantidad de asuntos diferentes que podía manejar, fueran finanzas, consejos, salarios, tributos, aduanas, privilegios legales o judiciales, oficios, pactos e infinitas otras materias, como si entendiera la completa anatomía del Estado. Consecuentemente no importaba qué tuviera entre manos, no había hombre en el Consejo con quien no pudiera debatir pros y contras, no podía salir con otra decisión mejor informada, 
ganándose la reputación a través de toda Europa de tener la mente más alerta y la mayor comprensión del arte de gobernar de su tiempo. Esta virtuosa princesa ha sido frecuentemente consejera de sus consejeros, y un oráculo en asuntos de estado, prediciendo de antemano qué iba a pasar a continuación”. Más allá de su gobierno, aconsejó al Emperador por correspondencia a cerca de innumerables asuntos". Richardot también remarcó la acertada administración de justicia por parte de María “dando los más y mejores remedios a todos los inconvenientes con el menor daño posible hacia los más pobres”, incluso “en tiempos difíciles con asuntos más urgentes”. Como la bíblica Débora “cumplió el rol de Juez, Gobernante y Capitán” puesto que incluso en asuntos militares hizo todo lo que fue posible. "Favor divino no le fue dado solo a los hombres, sino también a las mujeres. Dios ha honrado este sexo que a veces ha superado las virtudes de los hombres de su tiempo en el gobierno de los Estados". Richardot apunta que estas mujeres eran raras de ver, pero algunas se podían encontrar en todas las épocas, y "la perla y Fénix de las Damas de este siglo fue sin duda la reina viuda de Hungría” (Monter 2012, 102-103).

\section{Referencias bibliográficas}

Csepregi, Zoltán. 2005. "Court Priests in the Entourage of Queen Mary of Hungary". Mary of Hungary: The Queen and Her Court 1521 - 1531. Eds. Orsolya Réthelyi. Budapest: Budapesti Történeti Múzeum. 49-61.

De Iongh, Jane. 1958. Mary of Hungary: second regent of the Netherlands. London: Faber \& Faber.

Doyle, Daniel Robert. 1996. The Body of a Woman but the Heart and Stomach of a King: Mary of Hungary and the Exercise of Political Power in Early Modern Europe. Minesota: University of Minesota. 
Estella Marcos, Margarita. 2000. "El mecenazgo de la reina María de Hungría en el campo de la escultura". Carlos $V$ y las artes: promoción artística y familia imperial. Eds. María José Redondo Cantera y Miguel Ángel Zalama Rodríguez. Valladolid: Secretariado de Publicaciones e Intercambio Editorial. 321-322.

Gonzalo Sánchez-Molero, José Luis. 2008. "La biblioteca de María de Hungría y la bibliofilia de Felipe II". Marie de Hongrie. Politique et culture sous la Renaissance aux Pays-Bas. Eds. Bertrand Federinov, Bertrand y Gilles Docquier. Morlanwelz: Musée royal de Mariemont. 156-173.

2002. "La biblioteca de María de Hungría en España: corte, humanismo e inquisición”. España y las 17 provincias de los Países Bajos: una revisión historiográfica (XVI-XVII). Eds. Ana Crespo Solana y Manuel Herrero Sánchez. Córdoba: Servicio Publicaciones de la Universidad de Córdoba. 731-766.

Gorter-van Royen, Laetitia. 2008. "Les régentes de Charles Quint aux Pays-Bas: Marguerite d'Autriche et Marie de Hongrie". Marie de Hongrie. Politique et culture sous la Renaissance aux Pays-Bas. Eds. Bertrand Federinov, Bertrand y Gilles Docquier. Morlanwelz: Musée royal de Mariemont. 25-32.

Joan Kelly. 1984. Women, History and Theory: The Essays of Joan Kelly. Chicago: University of Chicago Press.

Klapisch-Zuber, Christiane. 1987. Women, Family and Ritual in Renaissance Italy. Chicago: University of Chicago Press.

Monter, William. 2012. The Rise of Female Kings in Europe, 1300-1800. New Haven: Yale University Press.

Réthelyi, Orsolya. 2010. Mary of Hungary in Court Context (1521-1531). Budapest: Central European University.

2008. "Ambiguous Loyalties? Mary as Queen of Hungary (1521-1526)". Marie de Hongrie. Politique et culture sous la Renaissance aux Pays-Bas. Eds. Bertrand Federinov, Bertrand y Gilles Docquier. Morlanwelz: Musée royal de Mariemont. 13-24.

Thompson, Glenda Goss. 1975. Benedictus Appenzeller: Maître de la Chapelle to Mary of Hungary and Chansonnier. Chapel Hill: University of North Carolina Press.

Sebastián Lozano, Jorge. 2005. Imágenes femeninas en el arte de corte español del siglo XVI. Valencia: Universidad de Valencia.

Splingart, Jean-Marc. 1994. Madame et son temps. Biographie de Marie de Hongrie. 1505-1558. Jumet: Imprimerie provincial.

Van den Boogert, Bob. 1993. "De Triomfen van de Keizer. De verheerlijking van Karel $\mathrm{V}$ en de toepassing van antieke motieven in de Nederlandse kunst". Maria van Hongarije. Koningin tussen keizers en kunstenaars 1505-1558. Eds. Bob van den Boogert y Jaqueline Kekhoff. Utrecht: Noordbrabants Museum. 220-268. 